Revista do Programa de Pós-Graduação em Educação da Unochapecó ISSN 1984-1566 (on-line) ISSN 1415-8175 (impressa)

\title{
O TENSIONAMENTO DA GESTÃO DEMOCRÁTICA E AS MUDANÇAS NAS ELEIÇÕES PARA DIRETOR ESCOLAR NO ESTADO DO PARANÁ
}

\author{
LA TENSIÓN DE LA GESTIÓN DEMOCRÁTICA Y LOS CAMBIOS EN LAS \\ ELECCIONES DE DIRECTORES DE ESCUELAS EN EL ESTADO DE PARANÁ
}

\author{
THE TENSIONING OF DEMOCRATIC MANAGEMENT AND CHANGES IN \\ ELECTIONS FOR SCHOOL DIRECTORS IN THE STATE OF PARANÁ
}

\author{
Andréia Paula Basei ${ }^{1}$ \\ ORCID: https://orcid.org/0000-0002-6675-6076
}

\begin{abstract}
Resumo
Neste artigo objetivamos compreender o debate sobre gestão democrática no ensino público em consonância com a Lei n. 18.590, de 15 de outubro de 2015 e as repercussões ocasionadas pela aprovação na Assembleia Legislativa do Paraná da Lei 20.358 de 26 de outubro de 2020, a qual promove mudanças nas eleições para diretor(a) das escolas da rede pública estadual, permitindo uma maior intervenção do Estado na escolha feita pela comunidade escolar. Recorrendo à análise documental e à análise temática de conteúdo, examinamos os documentos da legislação assim como a repercussão na mídia, o posicionamento de entidades sindicais e de agentes políticos. Constatamos que as mudanças propostas configuram mais um momento de tensionamento e cerceamento do poder da democracia e da gestão democrática no contexto político nacional e estadual que interfere no processo democrático, afronta os direitos sociais e a educação pública. Concluímos que as mudanças, ajustes e revisões na legislação devem ser fruto de debates democráticos que contemplem os direitos de todos os cidadãos, contrariamente às ações alienadoras para controle do Estado.
\end{abstract}

Palavras-chave: Gestão democrática. Eleição. Diretor escolar. Lei n. 20.358/2020-ALEP/PR.

\section{Resumen}

En este artículo pretendemos comprender el debate sobre la gestión democrática en la educación pública en línea con la Ley núm. 18.590, del 15 de octubre de 2015 y las repercusiones que ocasionó la aprobación en la Asamblea Legislativa de Paraná de la Ley 20.358 del 26 de octubre de 2020, que promueve cambios en las elecciones para director de escuelas en la red pública estatal, permitiendo una mayor Intervención estatal en la elección de la comunidad escolar. Mediante análisis documental y análisis de contenido temático, examinamos los documentos legislativos, así como la repercusión en los medios de comunicación, el posicionamiento de entidades sindicales y agentes

\footnotetext{
${ }^{1}$ Doutora em Educação. Professora do Departamento de Ciências do Movimento Humano, Universidade Estadual de Maringá, Campus Regional do Vale do Ivaí (DMO/UEM/CRV). Grupo de Pesquisa e Estudos em Políticas de Educação Física e Esportes (GEPEFE). E-mail: andreiabasei@yahoo.com.br
}

Como referenciar este artigo:

BASEl, A. P. O tensionamento da gestão democrática e as mudanças nas eleições para diretor escolar no estado do Paraná. Revista Pedagógica, v. 23, p. 1-26, 2021. 
políticos. Observamos que los cambios propuestos representan un momento más de tensiones entre la democracia y la gestión democrática en el contexto político nacional y estatal que interfiere en el proceso democrático, atenta contra los derechos sociales y la educación pública. Concluimos que los cambios, ajustes y revisiones en la legislación deben ser el resultado de debates democráticos que contemplen los derechos de todos los ciudadanos, en contraposición a acciones alienantes de control del Estado.

Palabras clave: Gestión democrática. Elección. Director. Ley n. 20.358/2020-ALEP/PR.

\begin{abstract}
In this article we aim to understand the debate on democratic management in public education in line with Law no. 18,590, of October 15, 2015 and the repercussions caused by the approval in the Legislative Assembly of Paraná of Law 20,358 of October 26, 2020, which promotes changes in the elections for director of schools of the state public network, allowing a greater State intervention in the choice made by the school community. Using documental analysis and thematic content analysis, we examine the legislation documents as well as the repercussions in the media, the positioning of union entities and political agents. We note that the proposed changes represent yet another moment of tensioning democracy and democratic management in the national and state political context that interferes in the democratic process, affront social rights and public education. We conclude that changes, adjustments and revisions in the legislation must be the result of democratic debates that contemplate the rights of all citizens, in contrast to alienating actions to control the State.
\end{abstract}

Keywords: Democratic management. Election. School principal. Law n. 20.358/2020-ALEP/PR.

\title{
INTRODUÇÃO
}

A gestão democrática em educação é um fenômeno complexo que está associado a mecanismos formais - ligados à normatização, tais como: leis, regimentos, decretos, entre outros e a instituições e instâncias administrativas, sejam Secretarias de Educação, Conselhos de Educação, etc - e as práticas cotidianas dos atores sociais nos sistemas e unidades de ensino. Assim, se constitui como foco de constantes disputas e debates em diferentes setores sociais, destacadamente no âmbito político. Circunscrito a esse universo, a temática da eleição para diretor escolar nas instituições públicas de ensino ganhou espaço em muitos debates no Brasil desde a década de 1980 - coincidindo com o período de redemocratização - com a finalidade de garantir mais um espaço para a efetivação da gestão democrática.

No percurso histórico da educação brasileira existem diferentes formas para a escolha dos diretores escolares. Na década de 1980, predominava a indicação do diretor pelos poderes públicos - estados e municípios -, a indicação por listas tríplices ou sêxtuplas, 
o diretor de carreira, a aprovação em concurso público e, em alguns casos, a eleição direta (DOURADO, 2001, p. 83). A partir desta década, influenciado pelas discussões acerca da gestão democrática na educação, as formas de escolha dos diretores também começaram a ser repensadas. E, embora ainda exista a escolha por indicação, através de concurso público e de aferição da competência técnica, a eleição ganha espaço em muitos municípios e Estados e passa a ser considerada como a forma de provimento mais democrática e coerente com os interesses da comunidade escolar. Conforme Souza e Pires (2018, p. 77), o Paraná figura como um dos poucos estados que têm legislação específica sobre o provimento de diretores por meio de eleições.

O que fica evidente é que a escola se constitui como um aparelho político e social e como objeto de disputas por se tratar de um espaço político-ideológico que pode se caracterizar como reprodutor, conservador ou transformador da realidade social. E nesse contexto, o diretor escolar, enquanto figura principal da equipe gestora, exercendo o papel de "[...] líder, mentor, coordenador e orientador principal da vida da escola e todo o seu trabalho educacional [...]" (LÜCK, 2009, p. 23) se constitui como foco de interesse nas disputas na arena política. Assim, pode-se afirmar, a partir das discussões na área, que se trata de um campo marcado por tensionamentos permanentes.

Quando falamos em tensionamento, nos referimos às relações de conflito entre dois ou mais polos necessários e insuperáveis. No contexto desta pesquisa, entre sociedade civil e Estado e os dissensos que envolvem a gestão democrática das escolas e do setor educacional como um todo. Sabemos, entretanto, que as relações conflitivas são processos inerentes à democracia e que representam as tensões existentes entre princípios opostos. O que caracteriza as relações entre esses polos são as marcas de tensionamentos permanentes. É importante considerar que, mesmo em vigência constante, as relações de tensionamento podem apresentar-se em graus variáveis, de modo que possam existir momentos de consenso.

Para compreendermos melhor estas relações, voltadas à temática da eleição para diretor escolar no Estado do Paraná, contextualizando-as com o cenário atual, o objetivo deste estudo é compreender o debate sobre gestão democrática no ensino público em consonância com a Lei n. 18.590, de 15 de outubro de 2015 e as repercussões ocasionadas pela aprovação na Assembleia Legislativa da Lei n. 20.358 de 26 de outubro de 2020, a qual 
promove mudanças nas eleições para diretor(a) das escolas da rede pública estadual, permitindo uma maior intervenção do Estado na escolha feita pela comunidade escolar.

Esse texto está estruturado em três seções, além desta introdução e dos encaminhamentos metodológicos. Inicialmente apresentamos uma breve incursão histórica pela legislação estadual atrelada a momentos e movimentos políticos no que se refere à temática da eleição para diretor escolar. Na segunda seção, abordamos a Lei n. 18.590/2015 e a Lei n. 20.358/2020 que propõe alterações nas formas de provimento do cargo no Estado. Na terceira seção, analisamos as repercussões desta proposição de mudanças nos cenários educacional, social e político por meio da pesquisa documental das matérias veiculadas pela mídia, a partir das quais refletimos sobre as relações de tensionamento que se estabeleceram no campo educacional.

\section{METODOLOGIA}

O artigo foi desenvolvido com base na análise documental, “[...] de materiais que não receberam ainda um tratamento analítico, ou que ainda podem ser reelaborados de acordo com os objetos da pesquisa" (GIL, 2008, p. 45). Os documentos são entendidos como registros escritos que possibilitam a compreensão dos fatos e relações, no caso desta pesquisa, proporcionam o conhecimento do conteúdo das leis, além do período histórico e social em que as ações se efetivam e das manifestações geradas e registradas de determinados grupos sociais. Os procedimentos metodológicos para análise envolveram a seleção, descrição, ordenação e posterior análise das informações.

As informações obtidas seguiram a análise temática de conteúdo, com base nas etapas anunciadas por Bardin (2011): pré-análise, análise do material, tratamento dos resultados, inferência e interpretação. Esse processo nos permitiu compreender e considerar conteúdos explícitos e implícitos nos documentos e matérias analisadas.

As análises (documental e de conteúdo) envolveram os documentos da Lei $\mathrm{n}$. 18.590, de 15 de outubro de 2015, do Projeto de Lei n. 565/2020 aprovado pelos deputados em 5 de outubro de 2020 e encaminhado à sanção legislativa em 14 de outubro de 2020, a Lei n. 20.358 de 26 de outubro de 2020, além de matérias jornalísticas e notas publicadas por representações sindicais e agentes políticos desde a apresentação do projeto de lei, 
em 21 de setembro de 2020 em regime de urgência até posterior a aprovação das emendas em $3^{\text {a }}$ discussão em 6 de outubro de 2020 e sanção da Lei n. 20.358/2020. Portanto, o material pesquisado foi composto por todas as matérias publicadas relacionadas à temática nos meses de setembro e outubro de 2020, além de matérias anteriores de agentes políticos ligados ao governo que já anunciavam possíveis mudanças.

A busca das matérias foi realizada no site de busca Google por meio de levantamento daquelas que apresentavam em seu conteúdo as palavras-chave: "eleição”, “diretor escolar”, “Lei n. 18.590/2015”, “Projeto de Lei 565/2020”, “Lei 20.358/2020”, "SEED Paraná". A escolha desses descritores se deu por serem considerados, a partir da leitura preliminar das matérias sobre o assunto, como relevantes para o tema proposto, pois são eles que nomeiam a temática nos meios de comunicação. As matérias foram impressas, e, em seguida, a sua identificação e leitura foram realizadas, procedendo-se à análise do material.

No tratamento das informações buscamos identificar e compreender os seguintes aspectos: o processo de eleição na lei e no projeto de lei; os impactos das mudanças propostas; o posicionamento das entidades sindicais; o posicionamento dos agentes políticos; e as repercussões na mídia estadual e nacional.

\section{ANTECEDENTES HISTÓRICOS: OS MOVIMENTOS POLÍTICOS NO CENÁRIO DA PESQUISA}

Desde a Constituição Federal de 1988 (BRASIL, 1988) a gestão democrática foi legalmente instituída como princípio constitucional. Consta no art. 206 que este princípio se fundamenta na possibilidade do compartilhamento do poder, no respeito às decisões colegiadas, na valorização da participação dos sujeitos envolvidos no processo educativo e na autonomia. Do mesmo modo, a Lei de Diretrizes e Bases da Educação Nacional n. 9.394/1996 (BRASIL, 1996) estabelece no art. $3^{\circ}$ a gestão democrática do ensino público. Nesse contexto, as formas de provimento do cargo de diretor escolar, enquanto espaço para atender aos princípios da gestão democrática, ganham destaque.

A eleição direta para diretor nas unidades de ensino no Paraná foi conquistada na década de 1980, mais especificamente, em 17 de julho de 1983, regulamentada pelo Decreto Lei n. 455/1983, o qual previa unicamente a forma paritária de votos. Participaram 


\section{REVISTA}

\section{Revista do Programa de Pós-Graduação em Educação da Unochapecó ISSN 1984-1566 (on-line) ISSN 1415-8175 (impressa)}

da eleição cerca de 2 milhões de pessoas em 3.500 escolas da rede estadual, o que representou mais de 70\% dos pais dos alunos (CUNHA, 1995, p. 247).

Este primeiro processo eleitoral foi resultado de lutas da sociedade em prol do Estado de direito, que estava sendo retomado após o período da ditadura militar em 1964. Todavia, o processo eleitoral não foi concluído de acordo com as expectativas dos profissionais da educação. Devido a pressão dos deputados, foi instituído que, com o resultado das eleições fosse elaborada uma lista tríplice com os nomes dos três candidatos mais votados, a qual foi encaminhada à Inspetoria Regional de Ensino, que anexava um parecer e encaminha-a para a Secretaria de Estado da Educação, para posterior nomeação do diretor (CUNHA, 1995). Apesar de, mais uma vez, a vontade política do governo se sobressair à vontade dos eleitores, a iniciativa da eleição foi considerada um avanço democrático para a época.

Conforme Cunha (1995), diante das críticas e do não cumprimento das promessas feitas nas eleições, nas quais tinha o apoio da entidade sindical que representava os professores, o então governador José Richa se comprometeu a fazer mudanças no processo eleitoral para o mandato seguinte. O Decreto Lei em vigor - n. 455/1983 - instituía também que em novembro de 1984 seria realizada uma nova eleição para diretor. Porém, a Assembleia Legislativa Estadual prorrogou o mandato dos diretores até o final de 1985 e, concomitantemente, o governador sancionou a Lei n. 7.961/1984, que extinguiu a lista tríplice, estabeleceu um mandato de dois anos e autorizou a reeleição. Essa Lei também estabeleceu que ficava a cargo do Secretário de Estado da Educação a nomeação de outro diretor no caso de vacância, desistência ou outros motivos de afastamento do cargo, contrariamente ao desejo das entidades sindicais cuja proposição era de que o segundo candidato mais votado assumisse o cargo até o fim do mandato.

Assim, permeadas pelos embates políticos, entre os anos de 1983 e 1989 ocorreram quatro eleições. Conforme Almeida (2004), em 1987, foram extintas as práticas de reeleição, não podendo se candidatar os já eleitos em 1983 ou 1985. As eleições de 1989 mantiveram tais especificações, dentre outras que foram previstas na Resolução n. 3846/87, porém, acrescentaram o veto à candidatura de professores e especialistas que estivessem no estágio probatório. Neste mesmo ano, foi publicada a Constituição do Estado do Paraná, a qual normatizou as eleições diretas estabelecidas em seu artigo 178, 
Inciso VII, onde estava previsto: "gestão democrática e colegiada das instituições de ensino mantidas pelo Poder Público estadual, adotando-se sistema eletivo, direto e secreto, na escolha dos dirigentes, na forma da lei" (PARANÁ, 1989).

Na década de 1990, marcada pelo avanço do neoliberalismo em todas as áreas e pela lógica empresarial que ganhou força nas escolas públicas, houve um retrocesso no processo eleitoral para o cargo. Em 1991, a eleição para o governo do Estado de Roberto Requião (PMDB - 1991-1994), culminou com a entrada de uma ação no Supremo Tribunal Federal (STF), solicitando a suspensão da eleição para diretores sob a alegação de inconstitucionalidade, sendo que em 7 de fevereiro de 1992, em votação unânime, a ação foi acatada pelo STF. Com esta medida, regulamentada pelo Decreto n. 849/1991, o diretor passou a ser designado pelo Estado após a consulta ao quadro da escola (PARO, 2003), o que expressa interesses antagônicos entre os agentes políticos e sociais e a autocracia do Estado evidenciando o controle do poder público.

Frente a esta forma de provimento instituída, o governo do estado implementou, com o Decreto n. 2.099/93, o conselho escolar como o órgão responsável pela consulta à comunidade escolar, além da Resolução n. 957/93, que dentre seus apontamentos, determina a apresentação de Plano de Ação do Candidato a Diretor nos mandatos de 19921993 e 1994-1995 (FEIGES, 2013).

No ano de 1995, com a eleição do governador Jaime Lerner - primeiro mandato 1995/1998, segundo mandato 1999/2003 -, o provimento do cargo de diretor para as próximas gestões (1996-1997; 1998-1999; 2000-2001) se configura novamente por eleições diretas pela comunidade escolar, porém, com algumas alterações, como por exemplo, a noção de chapa e o peso igual para votos de professores, alunos e funcionários (FEIGES, 2013). O Decreto n. 4.313/2001 institucionalizou novamente a eleição para o cargo de diretor. As inovações foram: o processo eleitoral precedido por uma prova eliminatória com o objetivo de avaliar as competências administrativas e gerenciais dos candidatos e o direito aos funcionários dos Núcleos Regionais de Educação (NRE) de votar, além dos alunos, pais, funcionários e professores, contudo com peso diferenciado entre os votos.

No ano de 2003, Roberto Requião foi novamente eleito e assumiu o governo do Estado por dois mandatos consecutivos (2003/2006 e 2007/2010). O governador eleito assumiu a bandeira da gestão democrática, com a finalidade de revitalizar a gestão da 
escola, otimizar a participação política e promover o enfrentamento ao modelo neoliberal do seu antecessor (RUIZ, 2015). Com a promulgação da Lei n. 14.231/2003, Requião normatizou as eleições para diretor, destacando a supressão da prova técnica e do direito de voto dos funcionários dos NRE's. Em 2006, passa a vigorar a Lei n. 15.329/2006, sendo que a única alteração foi o tempo de mandato, que era de dois anos e passou para três anos.

Dois anos mais tarde, a Resolução n. 4.202/2008 instituiu normas complementares para o processo de escolha de diretores. O documento estabeleceu o voto paritário e o direito ao voto para todos os membros da comunidade escolar - alunos, pais, professores e funcionários. Além disso, normatizou a realização de três assembleias, uma por turno, a divulgação em cada sala de aula, uma vez por chapa com o tempo máximo de 20 minutos e também, a apresentação de um Plano de ação para o mandato (PARANÁ, 2008).

Com a renúncia de Requião para concorrer ao senado, o vice-governador Orlando Pessuti assumiu o governo do Estado no período de abril a dezembro de 2010. Nesse período, é instituída a Lei n. 16.538 de 30 de junho de 2010 que dá nova redação ao §1. ${ }^{\circ}$, do artigo $1 .^{\circ}$, da Lei 14.231/2003:

$\S 1^{\circ}$ Excetuam-se da presente lei os Estabelecimentos de Ensino regidos nos termos dos convênios celebrados com a Secretaria de Estado da Educação, os que funcionam em prédios privados, cedidos ou alocados de instituições religiosas e os da Polícia Militar do Estado do Paraná (PARANÁ, 2010).

Dentre as alterações, destaca-se a instituição de uma comissão central na Secretaria de Educação do Paraná, responsável por coordenar o processo de consulta à comunidade escolar, havendo representantes dos diretores e também a mudança do prazo de mandato do diretor para três anos (eleições de 2006-2008, 2009-2011).

Em 2011, quando Beto Richa do Partido da Social Democracia Brasileira (PSDB) assumiu o governo do Paraná, foi mantido o processo de eleição direta de diretores que estava sendo realizado em governos anteriores. Neste mesmo ano, foi publicada pela Secretaria de Estado a Resolução n. 4122/2011 que regulamentou o processo de consulta à comunidade escolar para designação de diretores e diretores auxiliares.

Posterior às Leis n. 14231/03 e n. 15329/06, houve outras com disposições complementares por meio de resoluções e decretos que não instituíam significativas 
mudanças no processo. Com a revogação dessas leis, em 15 de outubro de 2015, é instituída a Lei n. 18.590, que trata da definição de critérios de escolha mediante a consulta à Comunidade Escolar para designação de Diretores e Diretores Auxiliares da Rede Estadual de Educação Básica do Paraná. Essa lei será apresentada e discutida na próxima seção deste texto, haja vista sua relação com o objeto de estudo, o Projeto de Lei (PL) que propôs alterações e gerou calorosas discussões desde sua apresentação inicial na Assembleia Legislativa.

Como é possível notar, a escolha dos diretores escolares, como um dos pilares da gestão democrática, foi e ainda é motivo de intenso debate no campo educacional, dialogando ou divergindo com a diversidade de concepções políticas, de educação e de sociedade. Desse modo, a seguir pretendemos analisar o que se prescreveu na Lei $n$. 18.590, de 15 de outubro de 2015, no Projeto de Lei n. 565/2020 aprovado pela Assembleia Legislativa do Paraná em 5 de outubro de 2020 e na Lei n. 20.358/2020, a qual promove mudanças nas eleições para diretor(a) das escolas da rede pública estadual, permitindo a intervenção do Estado na escolha feita pela comunidade escolar.

\section{A LEI n. 18.590/2015 E AS MUDANÇAS PROPOSTAS NA LEI n. 20.358/2020}

Nesta seção, apresentamos uma contextualização dos fatos em torno da legislação vigente - Lei n. 18.590, de 15 de outubro de 2015 - até a proposição do Projeto de Lei n. 565/2020 com o enunciado de mudanças e a sanção da Lei n. 20.358, em 26 de outubro de 2020.

Em 20 de agosto de 2015 foi apresentado a Assembleia Legislativa o Projeto de Lei n. 631/2015 cujo conteúdo se tratava da revogação das Leis n. 14231/03 e n. 15329/06 e apresentação de novos critérios de escolha mediante a consulta da comunidade escolar para a designação dos diretores escolares.

A Lei n. $18.590 / 2015$ estabeleceu em seu Art. $1^{\circ}$ que:

A designação de Diretores e Diretores Auxiliares da Rede Estadual de Educação Básica do Paraná é competência do Poder Executivo, nos termos desta Lei, mediante delegação da escolha à Comunidade Escolar, em consulta realizada simultaneamente em todos os estabelecimentos de ensino. 
Esta Lei, entretanto, já excluía da escolha da comunidade escolar as escolas: regidas por convênios ou congêneres celebrados com a Seed que prevejam outra forma de consulta para designação de Diretores; de comunidades indígenas e quilombolas; que funcionam em prédios privados, cedidos ou alocados de instituições religiosas, salvo previsão no respectivo instrumento; da Polícia Militar do Estado do Paraná e, das Unidades Prisionais e dos Centros de Socioeducação - Cense (PARANÁ, 2015).

Com a promulgação da nova legislação - Lei n. 20.358/2020 - foram incluídas nesta relação de estabelecimentos de ensino cujo provimento do cargo de diretor será por meio de indicação do governo do Estado, as escolas cívico-militares e as escolas de educação integral (PARANÁ, 2020). Fica evidente o interesse do governo em aumentar o quantitativo de estabelecimentos de ensino sob o seu controle, tendo em vista que os gestores indicados não são contrários às proposições do governo, tampouco questionarão suas ações. Essas ações deixam explícito o interesse em impor uma nova face à educação no Estado, alinhado aos preceitos do governo federal, no intuito de ceifar qualquer perspectiva de autonomia ou pensamento crítico.

Nos termos da lei de 2015, são considerados membros da comunidade escolar “[...] professores, funcionários, pais ou responsáveis e os alunos do estabelecimento de ensino onde se dará a designação dos Diretores e Diretores Auxiliares”. O provimento do cargo, conforme o Art. $3^{\circ}$ será feito "por meio de voto por chapa, direto, secreto, igualitário e facultativo aos membros da comunidade escolar aptos a votar", cuja realização das eleições está prevista “entre os meses de novembro e dezembro” (PARANÁ, 2015).

A nova legislação, não trouxe alterações com relação aos membros da comunidade escolar e a forma ou período de realização das eleições. Entretanto, propôs alteração no parágrafo primeiro do Art. $3^{\circ} \S 1^{\circ}$ o qual estabelecia que: “O período para a realização da consulta poderá ser alterado em decorrência de eventos que provoquem a paralisação das atividades dos estabelecimentos de ensino e incidam em alteração significativa do calendário escolar, mediante ato fundamentado da Seed" (PARANÁ, 2015), sendo incluído a este que, o período poderá ser também alterado "em decorrência de decretação de estado calamidade pública" (PARANÁ, 2020). Essa alteração, possivelmente, foi influenciada pela pandemia de Covid-19, que no ano de 2020 trouxe impactos em escala mundial para todos os setores sociais. Entretanto, vale lembrar que o governo chegou a 
anunciar o processo de eleição para diretor, divulgar editais e outros procedimentos e que a prorrogação dos mandatos se deu somente após grande pressão dos professores e entidades sindicais representativas alegando o risco à saúde pública.

No Art. $7^{\circ}$ da legislação de 2015, fica estabelecido a criação de uma comissão consultiva com a responsabilidade de acompanhar o processo de consulta para designação dos diretores, a qual é formada por: um representante da Superintendência de Educação Sued, um representante da Superintendência de Desenvolvimento Educacional - Sude, um representante do Grupo de Recursos Humanos Setorial - GRHS, um representante do Departamento de Legislação Escolar - DLE e, um representante do Departamento de Gestão Escolar - DGE (PARANÁ, 2015). Na lei de 2020, o representante da Superintendência de Desenvolvimento Educacional - Sude foi substituído por um representante do Instituto Paranaense de Desenvolvimento Educacional - Fundepar.

Além destas alterações, as mais polêmicas se relacionam aos Art. $9^{\circ}$ e $20^{\circ}$, quando mudam critérios para provimento do cargo. No Art. $9^{\circ}$ são estabelecidos os requisitos para o provimento do cargo. A Lei n. 18.590/2015 estabelecia:

\begin{abstract}
Art. 9. São requisitos para o registro da chapa que seus integrantes: I - pertençam ao Quadro Próprio do Magistério, ao Quadro Único de Pessoal, ao Quadro de Funcionários da Educação Básica ou ao Quadro Próprio do Poder Executivo; II possuam curso superior com licenciatura; III - componham o quadro do respectivo estabelecimento de ensino desde o início do ano letivo da consulta; IV - tenham disponibilidade legal para assumir a função, no caso de estabelecimento de ensino que tenha demanda de quarenta horas de direção; $V$ - tenham participado de Curso de Gestão Escolar específico em formação continuada, oferecido pela Seed, ou em parceria com outras instituições formadoras, ou do Programa de Desenvolvimento Educacional - PDE, na linha de estudo de Gestão Escolar, ou de Curso de Pós-Graduação lato ou strictu sensu, com ênfase em gestão escolar, comprovado mediante diploma reconhecido pelo Ministério da Educação. VI apresentem proposta de Plano de Ação compatível com o Projeto Político Pedagógico do respectivo estabelecimento de ensino e com as políticas educacionais da Seed (PARANÁ, 2015).
\end{abstract}

A atual legislação modificou os incisos III e V, os quais passam a vigorar com a redação: “III - componham ou tenham figurado no quadro do respectivo estabelecimento de ensino por no mínimo seis meses desde o início do ano letivo da consulta"; "V - tenham participado e concluído Curso de Gestão Escolar específico em formação continuada, oferecido pela SEED ou em parceria com outras instituições formadoras, previsto e disciplinado em ato específico" (PARANÁ, 2020). 
Já o Art. $20^{\circ}$ trata do afastamento do diretor do cargo de forma temporária - caso ocorra a instauração de processo administrativo e em decorrência de atraso ou de irregularidade na prestação de contas - ou de forma definitiva - em decorrência de condenação criminal, reprovação de prestação de contas, descumprimento do termo de compromisso firmado ao assumir a função, não participação ou aproveitamento inferior ao mínimo estabelecido no programa oficial de formação para gestão escolar da Seed e,

[...] insuficiência de desempenho da gestão administrativa-financeira, pedagógica ou democrática, apurada pelos setores técnicos competentes, a pedido do Conselho Escolar, aprovado por maioria absoluta da Comunidade Escolar, mediante votação convocada para essa finalidade, desde que essa convocação se dê mediante requerimento contendo assinaturas de 1/3 (um terço) do estabelecimento (PARANÁ, 2015).

A lei aprovada recentemente altera a alínea c do inciso II, a qual passa a vigorar com a seguinte redação:

c) insuficiência de desempenho da gestão administrativa-financeira, pedagógica ou democrática, apurada pelos setores técnicos competentes, a pedido da SEED ou do Conselho Escolar, aprovado por Comissão paritária, constituída por quatro membros, sendo dois membros do Conselho Escolar, dois membros da SEED, observados os princípios da ampla defesa e do contraditório, tendo, em caso de empate, o representante da SEED o voto de qualidade (PARANÁ, 2020).

As mudanças propostas evidenciam atitudes de interesse do Estado em detrimento do fortalecimento do controle social compatível com os interesses da comunidade escolar. A eleição, conforme Paro (2003) é um mecanismo criado para garantir o espaço que dá o direito à comunidade escolar em escolher seu dirigente, o qual possui a importante tarefa de gerir/administrar os rumos da escola. Todo esse processo é prejudicado ou até mesmo impossibilitado em um contexto em que a democracia é tensionada, tendo em vista, que a “[...] democracia não se concede, se realiza: não pode existir 'ditador democrático"” (PARO, 2008, pp. 18-19), e esta é a postura que as ações do governo têm evidenciado, as quais coadunam com a ascensão à presidência do país de um governo ultraconservador que se expressa pelos ataques à democracia e a educação pública.

Por fim, a nova resolução dispensa para o ano de 2020 a obrigatoriedade da conclusão do curso de Gestão Específico oferecido pela SEED, uma vez que, dados os prazos, não seria possível a oferta e realização do curso anterior ao período da eleição. 
Conforme consta no Art. $6^{\circ}$ :

\begin{abstract}
$\mathrm{Na}$ consulta referente ao ano de 2020 , de que trata o art. $3^{\circ}$ da Lei $n^{\circ} 18.590$, de 2015, será permitida a participação dos candidatos que tenham concluído Curso de Gestão Escolar específico em formação continuada, oferecido pela SEED, ou em parceria com outras instituições formadoras, ou do Programa de Desenvolvimento Educacional - PDE, na área de Gestão Escolar, ou de Curso de Pós-Graduação lato ou strictu sensu, com ênfase em gestão escolar, comprovado mediante diploma reconhecido pelo Ministério da Educação (PARANÁ, 2020).
\end{abstract}

Considerando que as alterações propostas impactam diretamente no processo de gestão democrática, na próxima seção buscamos analisar as repercussões ocasionadas pelas mudanças por meio da pesquisa de matérias veiculadas pelos meios de comunicação, as quais permitiram dar visibilidade a polêmica em torno das determinações impostas pelo novo documento e o posicionamento de diferentes atores do cenário educacional e político.

\title{
REPERCUSSÕES DA PROPOSIÇÃO DE MUDANÇAS NOS CENÁRIOS EDUCACIONAL, SOCIAL E POLÍTICO
}

No que concerne às matérias veiculadas pela mídia sobre a temática, a leitura na íntegra e a análise, permitiram a caracterização das mesmas. No período pesquisado, foram identificadas 71 matérias, sendo $62 \%(n=44)$ delas publicadas em jornais de circulação local e estadual, $12,7 \%(n=9)$ em sites de entidades sindicais representantes da categoria em nível estadual e nacional, 5,6\% ( $n=4)$ divulgados em blogs de jornalistas e escritores, 9,8\% $(n=7)$ em sites de emissoras de rádio, $7 \%(n=5)$ em sites pessoais de agentes políticos deputados estaduais e, 2,8\% $(n=2)$ no site da Assembleia Legislativa do Paraná (ALEP). Observou-se que, ao fazer a articulação dos descritores, muitas matérias apareciam repetidas, apenas reproduzindo informações já publicadas em outras fontes.

Quanto ao formato textual, prevaleceram as matérias publicadas com caráter informativo descritivo, $72 \%(n=51)$, seguido pelo formato opinativo ou dissertativoargumentativo $28 \%(n=20)$. As matérias de caráter informativo, apresentam como fonte de informação o site da ALEP, da APP-Sindicato, além de outros sites de notícias como G1 Paraná e RPC cujo alcance é expressivo em âmbito estadual, regional e nacional. No 
entanto, somente reproduzem discussões e posicionamentos disponibilizados pelas fontes citadas, sem apresentar um julgamento ou apreciação crítica sobre o conteúdo. Desta forma, para nossas análises, vamos considerar a análise de conteúdo dos textos no formato dissertativo-argumentativo, onde estão expressas as opiniões dos agentes políticos e sociais. No quadro 1 é possível observarmos os textos selecionados.

Quadro 1 - Matérias selecionadas para análise

\begin{tabular}{|c|c|c|}
\hline Data & Fonte/Site & Título da matéria \\
\hline $03 / 09 / 2019$ & $\begin{array}{l}\text { APP-Sindicato } \\
\text { https://appsindicato.org.br }\end{array}$ & $\begin{array}{l}\text { Ratinho Jr. quer alterar lei e prorrogar } \\
\text { mandatos de diretores(as) de escola. }\end{array}$ \\
\hline 04/09/2019 & $\begin{array}{l}\text { Central única dos trabalhadores (CUT) } \\
\text { https://www.cut.org.br/noticias }\end{array}$ & $\begin{array}{l}\text { PR: Ratinho Jr. quer alterar lei e prorrogar } \\
\text { mandatos de diretores de escola }\end{array}$ \\
\hline $31 / 03 / 2020$ & $\begin{array}{l}\text { APP-Sindicato } \\
\text { https://appsindicato.org.br }\end{array}$ & $\begin{array}{l}\text { APP-Sindicato denuncia tentativa de } \\
\text { restrição em eleição para direções escolares }\end{array}$ \\
\hline $21 / 09 / 2020$ & $\begin{array}{l}\text { APP-Sindicato } \\
\text { https://appsindicato.org.br }\end{array}$ & $\begin{array}{l}\text { Governo quer, novamente, alterar eleição de } \\
\text { diretores de escolas estaduais }\end{array}$ \\
\hline $22 / 09 / 2020$ & $\begin{array}{l}\text { CINTE - Nacional } \\
\text { https://www.cnte.org.br/index.php/menu/co } \\
\text { municacao/giro-pelos-estados }\end{array}$ & $\begin{array}{l}\text { [PR] Governo apresenta projeto que } \\
\text { permite interferências na eleição de } \\
\text { diretores das escolas estaduais }\end{array}$ \\
\hline $22 / 09 / 2020$ & $\begin{array}{l}\text { O Diário de Maringá } \\
\text { https://odiariodemaringa.com.br }\end{array}$ & $\begin{array}{l}\text { Governo apresenta projeto que permite } \\
\text { interferências na eleição de diretores das } \\
\text { escolas estaduais }\end{array}$ \\
\hline $23 / 09 / 2020$ & $\begin{array}{l}\text { https://porem.net/2020/09/23/a-escolha-e- } \\
\text { obedecer }\end{array}$ & A escolha é obedecer!!! A Lei sou eu. \\
\hline $24 / 09 / 2020$ & http://professorlemos.com.br/?p=265 & $\begin{array}{l}\text { Lemos alerta para projeto autoritário do } \\
\text { governo estadual na educação }\end{array}$ \\
\hline $24 / 09 / 2020$ & $\begin{array}{l}\text { https://capitalfm.com.br/app-sindicato- } \\
\text { rebate-lider-do-governo-e-diz-que-estado- } \\
\text { pode-interferir-nas-eleicoes-democraticas- } \\
\text { escolares/ }\end{array}$ & $\begin{array}{l}\text { APP-SINDICATO rebate líder do governo e } \\
\text { diz que estado pode interferir nas eleições } \\
\text { democráticas escolares }\end{array}$ \\
\hline $25 / 09 / 2020$ & $\begin{array}{l}\text { APP-Sindicato } \\
\text { https://appsindicato.org.br }\end{array}$ & $\begin{array}{l}\text { Defesa da gestão democrática das escolas } \\
\text { aconteceu nesta sexta (25) } \\
\text { Audiência debate projeto que altera o } \\
\text { processo de escolha de diretores(as) }\end{array}$ \\
\hline $25 / 09 / 2020$ & $\begin{array}{l}\text { Jornal Gazeta do Povo } \\
\text { https://www.gazetadopovo.com.br/parana }\end{array}$ & $\begin{array}{l}\text { Governo quer alterar escolha de diretores } \\
\text { de escolas e projeto gera polêmica }\end{array}$ \\
\hline $25 / 09 / 2020$ & http://tadeuveneri.com.br/noticias & $\begin{array}{l}\text { Veneri alerta para avanço do autoritarismo } \\
\text { no Paraná }\end{array}$ \\
\hline $25 / 09 / 2020$ & https://www.assembleia.pr.leg.br & $\begin{array}{l}\text { Em audiência, deputados de oposição } \\
\text { criticam projeto do executivo que altera } \\
\text { regras na escolha de diretores }\end{array}$ \\
\hline $29 / 09 / 2020$ & $\begin{array}{l}\text { http://www.pt-pr.org.br/Noticia/51047/com- } \\
\text { tratoraco-deputados-impedem-o-debate-e- } \\
\text { aprovam-projetos-do-governo-que-atacam- } \\
\text { democracia-no-ambiente-escolar }\end{array}$ & $\begin{array}{l}\text { Com tratoraço, deputados impedem o } \\
\text { debate e aprovam projetos do governo que } \\
\text { atacam democracia no ambiente escolar }\end{array}$ \\
\hline $05 / 10 / 2020$ & $\begin{array}{l}\text { Jornal Gazeta do Povo } \\
\text { https://www.gazetadopovo.com.br/parana }\end{array}$ & $\begin{array}{l}\text { Base aliada de Ratinho Jr. aprova mudanças } \\
\text { na escolha de diretores de escolas }\end{array}$ \\
\hline $05 / 10 / 2020$ & $\begin{array}{l}\text { APP-Sindicato } \\
\text { https://appsindicato.org.br }\end{array}$ & $\begin{array}{l}\text { Projeto que altera eleição para diretor(a) de } \\
\text { escola é aprovado com o voto de } 41\end{array}$ \\
\hline
\end{tabular}




\begin{tabular}{|l|l|l|}
\hline & & $\begin{array}{l}\text { deputados(as) - Líder do governo declarou } \\
\text { que deputados “atacados" por pessoas } \\
\text { dentro das escolas sabem como essa lei vai } \\
\text { funcionar }\end{array}$ \\
\hline 08/10/2020 & $\begin{array}{l}\text { https://www.naoviu.com.br/agora-diretores- } \\
\text { de-escolas-estaduais-do-parana-poderao-ser- } \\
\text { afastados-por-insuficiencia-de-desempenho/ }\end{array}$ & $\begin{array}{l}\text { Agora, diretores de escolas estaduais do } \\
\text { Paraná poderão ser afastados por } \\
\text { "insuficiência de desempenho" }\end{array}$ \\
\hline 27/10/2020 & $\begin{array}{l}\text { Blog } \\
\text { https://www.esmaelmorais.com.br/tag/educa } \\
\text { cao/ }\end{array}$ & $\begin{array}{l}\text { Professores x Ratinho Jr; educadores } \\
\text { lideram revolta de servidores públicos } \\
\text { contra governador do PR }\end{array}$ \\
\hline $\begin{array}{l}\text { APP-Sindicato (Núcleo Londrina) } \\
\text { https://www.applondrina.com/author/anders } \\
\text { on/ }\end{array}$ & $\begin{array}{l}\text { Com “tratoraço", projetos de Ratinho para } \\
\text { militarizar escolas e alterar eleição de } \\
\text { diretores(as) são aprovados }\end{array}$ \\
\hline 30/10/2020 \\
APP-Sindicato & $\begin{array}{l}\text { Educadores(as) ocupam a Seed } \\
\text { denunciando o desrespeito aos(às) PSS }\end{array}$ \\
\hline
\end{tabular}

Fonte: Elaborado pela autora (2020).

O volume de matérias publicadas que abordam o tema da eleição para diretor escolar no Paraná nos últimos dois meses evidencia a importância e repercussão das discussões nos âmbitos social, político e educacional.

Fica evidente nas matérias de caráter dissertativo-argumentativo o posicionamento contrário de representantes de entidades sindicais, assim como agentes políticos (deputados) de bases opostas ao governo e de outros atores sociais ligados ao campo educacional. A ausência de um processo de construção e debate que mobilizasse a comunidade escolar provocou a publicação de manifestos de apoio da sociedade civil sindicatos, movimentos sociais - e de agentes políticos de oposição ao governo ressaltando a insatisfação com as alterações propostas. Para ilustrar, trazemos alguns trechos de matérias em que esses posicionamentos são bastante incisivos.

Conforme o presidente da APP-Sindicato, o professor Hermes Silva Leão,

O governador e seus deputados estão aproveitando a pandemia e as sessões virtuais para atacar a educação pública. Isso é covardia e autoritarismo, duas coisas que jamais deveriam acontecer em um regime democrático. [...] Nós repudiamos esse método autoritário, essa forma intervencionista do governo sobre as comunidades escolares, essa falta de diálogo e debate diante de temas tão importantes para a gestão democrática das escolas. (https://appsindicato.org.br., 05/10/2020).

Os deputados estaduais que compõem a bancada de oposição são contrários à proposta e figuram entre os agentes políticos com as manifestações mais recorrentes nas matérias encontradas. Dentre estes, o Professor Lemos (PT), líder da bancada de oposição, 


\section{REVISTA}

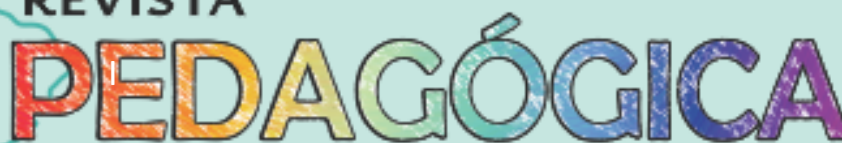

\section{Revista do Programa de Pós-Graduação em Educação da Unochapecó ISSN 1984-1566 (on-line) ISSN 1415-8175 (impressa)}

emite posicionamentos desde o primeiro anúncio que o projeto tramitaria em regime de urgência na ALEP. Conforme ele, com o referido Projeto o governo pretende "tutelar todos sob o comando de regras rígidas, sem liberdade de ensino e aprendizado" (https://www.assembleia.pr.leg.br, 22/09/2020).

É um projeto que fere profundamente a gestão democrática das escolas da rede estadual. Ele modifica os critérios para eleição dos diretores e também para cassar os mandatos desses profissionais, que são eleitos pela comunidade escolar, quando bem entender (https://www.assembleia.pr.leg.br, 22/09/2020).

Anterior ao primeiro debate na ALEP, o deputado Lemos se manifesta afirmando: “O projeto é polêmico, pois retira o poder da comunidade escolar dado pela Constituição, fazendo uma mudança significativa na lei atual. Necessitamos promover um debate profundo. A falta de democracia é preocupante" (https://www.assembleia.pr.leg.br, 25/09/2020).

Em matéria disponibilizada no site do Partido dos Trabalhadores em 29 de setembro o deputado reitera:

O projeto de lei 565/2020 interfere diretamente na eleição dos diretores e diretoras das escolas. Mas para além disso, ele retira da comunidade escolar o direito à liberdade de ensino e aprendizagem. É um projeto conservador, e conservadorismo é um retorno ao passado. Ele contraria a ciência e a escola é o espaço da ciência. A nossa Constituição garante a liberdade de ensinar e aprender com pluralidade. Não se pode elaborar um currículo conservador, que dita comportamento dos educadores e dos estudantes. Este projeto contraria a nossa Constituição, por isso somos contra. (https://www.pt-pr.org.br/Noticia/51047, 29/09/2020).

Considerando também o Projeto de Lei n. 543/2020 que trata da implantação de um programa de gestão cívico-militar em 215 escolas paranaenses, que tramitou de forma concomitante ao Projeto de Lei com as mudanças nas eleições para diretor escolar, o deputado afirma:

São projetos combinados, apresentados para fazer que nossas escolas preparem uma outra sociedade, diferente desta que respeita a pluralidade de ideias, que respeita as várias formas pedagógicas de se trabalhar. Os projetos vão enquadrar, acabar com criatividade e a diversidade no ambiente escolar, não é libertador, não é emancipador. Vai tutelar todos aqueles que ficarem sob o comando de regras rígidas, sem liberdade de ensino e aprendizado. (https://www.ptpr.org.br/Noticia/51047, 29/09/2020). 
Na data da aprovação final do PL, o deputado Professor Lemos (PT), assevera: “o projeto é inconstitucional, reduz a democracia nas escolas e as emendas são um remendo que não salvam o projeto" (https://appsindicato.org.br., 05 /10/2020).

Para a deputada Luciana Rafagnin (PT), "O projeto fere a democracia da educação do Paraná. Ao tirar a autonomia de trabalho dos diretores, retira o direito da comunidade de participar da escolha, afastando-a da escola" (https://www.assembleia.pr.leg.br, 25/09/2020). Fica evidente que o silenciamento de importantes vozes no processo de construção desta legislação, a caracteriza como parte de um projeto autoritário que retira direitos conquistados pelos sujeitos desse processo e interfere diretamente na forma de condução dos processos democráticos no âmbito escolar. Ainda conforme a deputada,

A mudança das regras para eleição de diretores das escolas é muito ruim. Ele retira o direito de a escola e a comunidade escolar elegerem os seus diretores. Ou seja, a direção passará a ser um cargo de indicação do governo. Isso é muito ruim. Somos contra e não concordamos com essa proposta. Precisamos respeitar o processo democrático e a escolha da comunidade escolar. Nós queremos que o cargo de direção continue sendo ocupado pelos profissionais da educação, que são pessoas que estão atuando no dia-a-dia e conhecem muito bem as escolas. Por isso precisamos analisar com responsabilidade esses projetos. Não podemos concordar com a derrota da democracia. (http://www.pt-pr.org.br/Noticia/51047, 29/09/2020).

De acordo com Paro (2011) a nomeação por critério político, em que o secretário de educação ou o chefe do poder executivo escolhe o ocupante do cargo, tendo como base o critério político-partidário, é comumente considerada a pior alternativa, em virtude do clientelismo político que ela alimenta e a falta de base técnica que a sustente, já que o candidato é escolhido não por sua experiência e conhecimento de gestão e de educação, mas por sua afinidade com o partido ou o grupo do governo. A criação e a exigência do curso de Gestão escolar para os possíveis diretores, por si só, não garantem, de forma específica, conhecimentos e habilidades aprofundadas em gestão, tampouco, de forma geral, conhecimento político do campo educacional.

Paro (2011) aponta ainda que, a argumentação dos adeptos dessa alternativa se refere à legitimidade do ato, pois o povo elegeu o governante e este tem a prerrogativa, garantida em lei, de escolher seus auxiliares, para pôr em execução a política de governo sufragada nas urnas. Entretanto, tais processos podem “[...] materializar-se em ações que visam não o interesse público, mas os interesses (privados) dos diretores e dos grupos 
políticos que os indicaram e a quem eles servem, em última instância”. Desta forma, tratase de “[...] uma alternativa antidemocrática aos olhos de todos, de tal modo que só muito raramente se encontra alguém, entre os educadores, funcionários e usuários da escola que se declare favorável a essa medida" (PARO, 2011, p.38), o que pode ser evidenciado pelo descontentamento e as repercussões que as atuais mudanças têm provocado.

Arilson Chiorato, também deputado do PT, avaliou que "Esta é mais uma barbárie contra os professores e o serviço público. Estamos preocupados com o fim do regime democrático dentro das escolas. Esta medida é injusta demais" (https://www.assembleia.pr.leg.br, 25/09/2020). O deputado também faz suas análises considerando o PL n. 543/2020, devido a sua tramitação simultânea.

Eu gostaria de perguntar: em que mundo vive o governo Ratinho Junior? Nós temos problemas de investimentos em infraestrutura, de valorização dos profissionais, de falta de alimentação nas escolas e o governo resolve defender e discutir projetos dessa natureza. O projeto 543/2020 é muito delicado e precisa de mais tempo para ser debatido. $O$ que estamos vendo aqui é um processo que sucumbe o projeto pedagógico ao projeto administrativo das escolas. É uma disputa ideológica. Não adianta falar que vai ter eleição e a comunidade vai decidir se quer colégio cívico-militar ou não. Política pública passa por fundamentação científica. Precisamos pensar em soluções concretas para os problemas da educação no Paraná. Somos contra essas propostas. Faltou debate, faltou construção coletiva com a comunidade escolar. É mais um dos muitos atos desrespeitosos do governo para com o povo do Paraná. (http://www.ptpr.org.br/Noticia/51047, 29/09/2020).

Tendo em conta a fala do deputado, é importante ressaltar as considerações de Souza e Pires (2018), sobre a importância de acompanharmos as formas de elaboração e o conteúdo das legislações sobre a gestão democrática, seja em nível estadual ou municipal, pois uma lei que trate da democracia tem que se pretender democrática, o que implica no envolvimento dos distintos segmentos e setores da sociedade na sua formulação. A disposição ao diálogo entre esses sujeitos é determinante na qualidade da lei e potencialmente contribuirá para a ampliação das chances do seu cumprimento. O que fica evidente na fala do deputado supracitado, e ao acompanharmos o processo das mudanças é que este processo de discussão com toda a comunidade escolar não ocorreu, além de sua tramitação acelerada na assembleia.

O líder do PT na Assembleia Legislativa, por sua vez, foi incisivo ao criticar as mudanças propostas e afirmar que o governo Ratinho Júnior está "passando a boiada", 


\title{
REVISTA
}

assim como faz o governo federal. De acordo com ele,

\begin{abstract}
Temos visto algumas situações que eram negadas em período eleitoral e que hoje fazem parte da gestão do atual governo. O projeto 565/2020, entre outras coisas, retira da comunidade escolar a prerrogativa de escolher os diretores das escolas. Este projeto possibilita interferência direta do governo do Estado, matando de vez a democracia dentro das escolas. Estamos vivendo um período de exceção. Estão passando a boiada aqui no Paraná, assim como faz o governo Bolsonaro. Vamos ter em 2021 um estado muito diferente daquele que imaginávamos em 2018, um estado perdendo muito na sua democracia. (http://www.ptpr.org.br/Noticia/51047, 29/09/2020).
\end{abstract}

No entendimento do deputado,

O governo do Estado infelizmente está num processo de progressão de autoritarismo extremamente forte. Não é por acaso que vem agora esse projeto de tirar a autonomia da comunidade escolar de escolher os seus diretores. Vivemos um retrocesso de 20 anos. (https://www.assembleia.pr.leg.br, 25/09/2020).

As falas corroboram no entendimento de que a escolha de diretores através de indicação vincula o trabalho do diretor com quem o indicou, quase sempre um político ou técnico das Secretarias de Educação. Seu compromisso, portanto, é com quem o colocou naquele cargo e não com a comunidade escolar. Nesse caso, "o papel do diretor, ao prescindir do respaldo da comunidade escolar caracteriza-se como instrumentalizador de práticas autoritárias, evidenciando forte ingerência do Estado na gestão escolar" (DOURADO, 2001, p. 83).

Assim, o líder do partido considera que os deputados da bancada de oposição têm um papel de suma importância na defesa dos interesses dos paranaenses e destaca:

\begin{abstract}
Nós temos a obrigação de fazer esse alerta. Não fomos eleitos para agradar o governo, mas para defender os interesses do povo paranaense. Estamos tendo nesse período de pandemia mais pedidos de Comissão Geral do que tivemos nos últimos anos do governo Beto Richa (PSDB). (http://www.ptpr.org.br/Noticia/51047, 29/09/2020).
\end{abstract}

No que se refere ao julgamento das entidades sindicais sobre a proposta, as matérias destacam a nota emitida pela direção estadual da APP-Sindicato, a qual condena a proposta do governador Ratinho Junior e do secretário de educação Renato Feder, especialmente, no que se refere à realização de cursos de formação. 
A realização de cursos de formação deve ser uma preocupação constante da Secretaria de Educação, como base para o aperfeiçoamento e melhorias da escola pública. No entanto, não deve ser utilizado como método para restringir direitos da categoria no processo de escolha das direções escolares. (https://appsindicato.org.br, 21/09/2020).

As matérias selecionadas da APP-Sindicato trazem a fala do presidente Hermes Leão que, em março de 2020, ao primeiro pronunciamento do governador sobre as possíveis mudanças já alertou: "O processo deve ser democrático, com participação de toda a comunidade. Não aceitaremos interferência do secretário. O processo deve ser acompanhado pelos núcleos e escolas com comissões consultivas eleitorais" (https://appsindicato.org.br, 31/03/2020).

Ainda sobre o posicionamento da APP-Sindicato, durante a tramitação da proposta a professora Walkiria Mazeto, secretária de finanças afirma:

Somos contrários às alterações propostas porque elas ferem diretamente o processo democrático. O Paraná foi um dos primeiros estados que passaram a respeitar a vontade da comunidade escolar na escolha das direções de escola. Isso é histórico e sempre foi reconhecido no país como um avanço. (https://appsindicato.org.br, 25/09/2020).

Para a professora, "A construção do processo democrático passa pela escola” e a aprovação do PL "acaba com a garantia do processo democrático, porque a comunidade pode escolher e a Seed, por razão dela, dizer que não quer e colocar outro no lugar, à revelia" (https://appsindicato.org.br, 25/09/2020).

Diante disso, trazemos as reflexões e o alerta feito por Paro (2003) de que a falta de autonomia do diretor reflete também a falta de autonomia da escola, ou seja, se em algum momento o processo democrático é subsumido por práticas autoritárias, estas práticas podem se tornar frequentes em distintas ações no interior da escola. Assim, ao aproximarmos a discussão acerca da eleição para diretores e sua relação com o PL e a nova legislação, é perceptível sua inclinação em defesa da lógica gerencial, haja vista que o estabelecido está preocupado em criar critérios para a escolha, mas não, necessariamente, para a democratização do processo.

A referida professora também critica a implantação do curso de formação em gestão escolar oferecido pelo governo como critério para ocupar o cargo: 
Além de não reconhecer cursos de gestão escolar feitos em outras instituições, como pós-graduação em Gestão Escolar e o próprio PDE em Gestão Escolar oferecido pelo Estado, a Seed está dizendo que vai fazer uma primeira escolha de quem pode ser candidato. Quem passar nesse crivo, quem sobrar, pode colocar o nome para a comunidade escolher. Isso é interferência no processo democrático. [...] O governo parte do pressuposto de que o trabalhador da educação não teria competência para ser diretor de escola. Nós discordamos disso e sempre defendemos que, uma vez eleito, sim, tenha um curso de gestão para se apropriar de dados e ferramentas técnicas. (https://appsindicato.org.br,05/10/2020).

Corrobora com este posicionamento, as discussões de Paro (2011, p. 45), a o afirmar que "numa gestão democrática, todos os educadores são potenciais candidatos à direção escolar, não justificando diferenças em sua formação". Sob o argumento de que,

[...] se se considera o caráter político (educativo) de sua função, tem-se que admitir que sua habilidade política é adquirida no exercício mesmo da política. Se assim não for e se, numa posição tecnicista, advogarmos um aprendizado técnico para exercer suas funções, então teríamos que exigir diploma de 'administração' também de prefeitos, governadores, deputados, senadores, presidentes da república etc, etc" (PARO, 2011, p. 45).

Além desses agentes, também encontramos as manifestações de outros, ligados à educação. A conselheira do Conselho Estadual de Educação, Taís Mendes, afirma: “Estamos vendo a gestão democrática definhar nas escolas. Não podemos deixar que as condições conquistadas ao longo do tempo sejam tolhidas. É inaceitável” (https://www.assembleia.pr.leg.br, 25/09/2020). Para o diretor do campus do Instituto Federal do Paraná na cidade de Jacarezinho, Rodolfo Fiorucci, “O projeto é retrógrado e pretende levar a educação do Paraná à meados do século XX com este modelo obsoleto" (https://www.assembleia.pr.leg.br, 25/09/2020).

Já o professor Ângelo Ricardo de Souza, da Universidade Federal do Paraná (UFPR), avalia que a questão é preocupante, pois altera conquistas emblemáticas da comunidade escolar. Ele enumerou uma série de pontos considerados polêmicos do PL, como a possibilidade de abertura de processo administrativo contra diretores e o artigo que retira a necessidade de o candidato a diretor estar trabalhando há pelo menos seis meses na instituição de ensino e conclui: "Infelizmente é um retrocesso muito grande" (https://www.assembleia.pr.leg.br, 25/09/2020). O professor atua como pesquisador no âmbito das políticas públicas educacionais e da gestão democrática a mais de duas décadas e seus estudos reafirmam seu posicionamento diante das discussões atuais: 
[...] indicar política ou tecnicamente o dirigente escolar pressupõe compreender a direção da escola pública não como uma função a ser desempenhada por um especialista da carreira do magistério, mas como um cargo político de confiança do governante municipal ou estadual ou como instrumento de compensação no jogo político-eleitoral (SOUZA, 2007, p, 166).

Segundo Paro (2011, p. 39) “[...] a escolha que mais se adequa às peculiaridades da função do diretor é a sua eleição pela comunidade escolar". Todavia, o autor ressalta que “isso não significa nenhuma certeza em termos de completa democratização da escola, já que é apenas uma das medidas necessárias. Entretanto, a eleição é a única que tem a virtude de contribuir para o avanço de tal democratização".

No que se refere aos posicionamentos favoráveis à proposta, não existe destaque nas matérias analisadas. Embora a aprovação do PL ocorreu com aproximadamente 30 votos de diferença, a única fala em destaque é do líder do governo, Hussein Bakri (PSD): “nós que já fomos atacados aqui durante um período, por várias pessoas dentro das escolas, sabemos como esse projeto vai funcionar" (https://appsindicato.org.br, 05/10/2020).

O que fica evidente na fala é que a proposta de alteração visivelmente busca interferir na gestão das escolas de maneira que elas não se posicionem contrárias ao governo, pois considerando os antecedentes históricos, sempre existiram embates e enfrentamentos com os governos numa permanente disputa de poder, de concepção de gestão e nas reivindicações por melhores condições de trabalho ou reajustes nos salários, por exemplo. Com a nova legislação, mais do que nunca, o diretor será como um preposto do Estado na escola, como "a mão do Estado", cujo papel se limita a controlar, dirigir, exercer o poder disciplinar e repassar orientações dos órgãos superiores.

Assim, ao analisarmos as relações de tensionamento entre Estado e atores políticos e sociais do campo da educação, percebemos que essas relações não se baseiam apenas na busca e consolidação de canais de participação ou na criação de consensos, mas, na expressão de subjetividades políticas e demandas, que nem sempre conseguem ressoar nas esferas públicas.

\section{CONSIDERAÇÕES FINAIS}


O que apresentamos neste texto evidenciou as formas como o estado do Paraná têm se organizado em relação ao princípio constitucional da gestão democrática relacionado ao processo de eleição para diretor escolar, especificamente as repercussões ocasionadas pelas mudanças propostas pela Lei n. 20.358/2020. Além de melhor perceber o funcionamento das transições entre as legislações e os movimentos políticos que envolvem a questão, procuramos entender como a gestão democrática, e, em particular, as lutas pela democracia, voltadas às demandas da educação pública, repercutem na mídia, entre as entidades sindicais e os agentes políticos.

Dadas as exigências feitas pela Constituição Federal de 1988, pela LDB de 1996, pelo PNE de 2014, dentre outros documentos e legislações, o Estado tem a responsabilidade de normatizar em sua área o alcance e os procedimentos que garantem a implementação da gestão democrática. Entretanto, as evidências mostram que a efetivação desse processo é, constantemente, tensionada pois a gestão democrática compreende um movimento histórico e contextualizado, e como fenômeno político, é perpassada por disputas de sentido e poder (BORDIGNON; GRACINDO, 2008).

Assim, na análise do material deste estudo, temos um quadro de retrocesso da legislação estadual sobre a gestão democrática no processo de escolha dos diretores escolares, o qual não se mostra capaz de traduzir o princípio democrático em regramentos para os seus sistemas. Fica explícito que as políticas educacionais em curso se ajustam àquelas propostas pelo governo federal com a implementação de medidas pragmáticas e alienadoras que desvalorizam os profissionais da educação, rebaixam a qualidade da educação pública, assim como o grau de consciência política.

O levantamento realizado ressalta a importância de acompanharmos as formas de elaboração e o conteúdo das legislações sobre a gestão democrática nos estados, pois uma lei que trata da democracia tem que se pretender democrática, o que implica no envolvimento dos distintos segmentos e setores da sociedade na sua formulação assim como na efetivação dos processos de escolha.

O acompanhamento sistemático das publicações em âmbito estadual e com repercussão nacional sobre as mudanças no processo de eleição para diretor escolar no Paraná permitiu-nos constatar movimentos de "volta ao passado". Como exemplo, 
retomamos as semelhanças do momento atual com o ocorrido na década de 1980. Em 1984 ocorreu a prorrogação dos mandatos até final de 1985, de modo semelhante ao ocorrido em 12 de novembro de 2019 quando a ALEP prorrogou o mandato dos diretores até o final de 2020 sob a justificativa do governo de que "o ano de 2019 configurou-se como um ano letivo atípico, ante a paralisação das aulas no período de 25 de junho a 12 de julho, em decorrência da greve do funcionalismo público" (ALEP, 2019). Importante destacar que neste ato, o líder do Governo na Casa, deputado Hussein Bakri (PSD), afirmou que não existiriam mudanças nas regras vigentes: "Será tudo exatamente como está previsto na lei que criou a eleição dos diretores", referindo-se à Lei 18.590/2015.

As contradições se relacionam também a outros episódios, uma vez que, o secretário de Estado da Educação, Renato Feder, afirmou no primeiro semestre de 2019 que alteraria o processo de eleição para diretores de escola, informando que seriam instituídos critérios para que os candidatos pudessem participar da eleição. Rejeitando estas mudanças a APP- Sindicato destacou este assunto nas pautas da greve de junho e julho de 2019, tendo a aceitação do governo ao final da greve em manter a legislação atual sem mudanças. Articulado a essa conjuntura, seis meses depois, o governo novamente anuncia mudanças no processo de eleição. Essa medida foi avaliada pela APP-Sindicato como uma nova tentativa do governador e do secretário da educação, de interferir no processo de eleição para diretores de escola.

Diante dos fatos, vivemos num período de mais tensões que avanços, de uma democracia tensionada pelo cerceamento de seu poder. As mudanças, ajustes e revisões na legislação são necessárias, porém, devem ser fruto de debates democráticos que contemplem os direitos de todos os cidadãos, visando a qualidade da educação e, neste caso específico, do processo de gestão e não a submissão e a expressão de autoritarismo pelo controle do Estado, tendo em vista que, escolher um diretor é escolher os rumos e a qualidade dos processos de gestão da escola (BORDIGNON; GRACINDO, 2008).

Portanto, é importante reforçar o entendimento de que a gestão democrática da educação implica, sobretudo, na primordialidade de uma postura democrática dos gestores, seja em nível estadual ou local, e que desta forma atuem no processo decisório contribuindo para consolidar o movimento democrático e trazer avanços para a educação. 
Revista do Programa de Pós-Graduação em Educação da Unochapecó

ISSN 1984-1566 (on-line) ISSN 1415-8175 (impressa)

\section{REFERÊNCIAS}

ALMEIDA, José Luciano Ferreira de. Concepções de gestão escolar e eleição de diretores da escola pública do Paraná. 2004. 201f. Dissertação (Mestrado em Educação) Universidade Federal do Paraná, Curitiba, 2004.

BARDIN, Laurence. Análise de conteúdo. São Paulo: Edições 70, 2011.

BORDIGNON, Genuíno; GRACINDO, Regina Vinhaes. Gestão da educação: o município e a escola. In. FERREIRA. Naura S. C.; AGUIAR. Márcia Angela da S. (Org.). Gestão da educação: impasses, perspectivas e compromissos. São Paulo: Cortez, 2008.

BRASIL. Constituição Federal de 1988. Disponível em: http://www.planalto.gov.br/ ccivil_03/Constituicao/Constituicao.htm. Acesso em: out. 2020.

BRASIL. Lei de Diretrizes e Bases da Educação Nacional, Lei n. 9.394/1996, de 20 de dezembro de 1996. Disponível em: http://www.planalto.gov.br/ccivil_03/leis/L9394. htm. Acesso em: out. 2020.

BRASIL. Lei do Plano Nacional de Educação, Lei n. 13.005/2014. Disponível em: http://www.planalto.gov.br/ccivil_03/_at02011-2014/2014/lei/l13005.htm. Acesso em: set. 2020.

CUNHA, Luiz Antônio. Educação, estado e sociedade no Brasil. 2. ed. São Paulo: Cortez, 1995.

DOURADO, Luiz Fernandes. A escolha dos dirigentes escolares: políticas e gestão da educação no Brasil. In: FERREIRA, Naura Syria Carapeto. Gestão democrática da Educação: atuais tendências, novos desafios. São Paulo: Cortez, 2001.

FEIGES, Maria Madselva Ferreira. Eleição de diretores no Paraná: uma análise dos planos de ação na gestão das escolas estaduais de Curitiba - triênio 2012-2014. 2013. 204f. Tese Setor de Educação - Universidade Federal do Paraná, Curitiba, 2013.

GIL, Antônio Carlos. Como elaborar projetos de pesquisa. 4. ed. São Paulo: Atlas, 2008.

LÜCK, Heloísa. Dimensões de gestão escolar e suas competências. Curitiba: Editora Positivo, 2009.

PARANÁ. Decreto n 455 de 19 de abril de 1983. Regimento de eleição para diretor de escola. Diário Oficial do Estado do Paraná, Curitiba, 1983.

PARANÁ. Governo do Estado. Lei n. 16.538, de 30 de junho de 2010. Dá nova redação ao § $1^{\circ}$, do artigo $1^{\circ}$, da Lei $n^{\circ} 14.231$, de 26 de novembro de 2003 , que dispõe sobre consulta para designação de Diretores e Diretores Auxiliares dos estabelecimentos de ensino.

Diário Oficial do Estado do Paraná, Curitiba, 30 jun. 2010. 
PARANÁ. Lei n. 18.590 de 13 de outubro de 2015. Diário Oficial n. 9.556 de 15 de Outubro de 2015. Disponível em:

<http://www.legislacao.pr.gov.br/legislacao/pesquisarAto.do?action=exibir\&codAto=1478 37\&codltemAto=904158\#904158>. Acesso em: set. 2020.

PARANÁ. Lei n. 20.358 de 26 de outubro de 2020. Diário Oficial n. 10.798 de 26 de outubro de 2020. Disponível em: <http://portal.assembleia.pr.leg.br/index.php/pesquisalegislativa/legislacao-estadual?idLegislacao=53924\&tpLei=0\&idProposicao=94084> . Acesso em: set. 2020.

PARANÁ. Projeto de Lei n. 565/2020. Assembleia Legislativa do Paraná. Disponível em: <http://portal.assembleia.pr.leg.br/modules/mod_legislativo_arquivo/mod_legislativo_ar quivo.php?leiCod=94084\&tipo=l>. Acesso em: set. 2020.

PARO, Vitor Henrique. Eleição de Diretores: a escola pública experimenta a democracia. São Paulo: Xamã, 2003.

PARO, Vitor Henrique. Gestão democrática da escola pública. 3. ed. São Paulo: Ática, 2008.

PARO, Vitor Henrique. A educação, a política e a administração: reflexões sobre a prática do diretor de escola. Educação e Pesquisa, v. 36, n.3, p. 763-778, set./dez. 2010.

PARO, Vitor Henrique. Escolha e formação do diretor escolar. Cadernos de Pesquisa: Pensamento Educacional, v. 6, n. 14, p. 36-50, set./dez. 2011.

RUIZ, Maria José Ferreira. A democratização da escola pública no estado do Paraná (1983 - 2010). Londrina: Eduel, 2015.

SOUZA, Ângelo Ricardo de; PIRES, Pierre André Garcia. As leis de gestão democrática da Educação nos estados brasileiros. Educar em Revista, v.34, n.68, 2018.

SOUZA, Ângelo Ricardo de. Perfil da Gestão Escolar no Brasil. 2007. 302f. Tese (Doutorado em Educação) - Programa de Pós-Graduação em Educação, Pontifícia Universidade Católica de São Paulo, São Paulo, 2007.

Recebido em: 14-12-2020

Aprovado em: 21-02-2021

Publicado em: 05-04-2021 